\title{
Reseña
}

\section{The snakes of Honduras: sytematics, distribution, and conservation McCranie, J. R. 2011. Society for the Study of Amphibians and Reptiles, Ithaca, New York, 714 p.}

\author{
Oscar Flores-Villela
}

Museo de Zoología, Facultad de Ciencias, Universidad Nacional Autónoma de México, Apartado postal 70-399, 04510 México, D. F., México. 凶ofvq@unam.mx

Para continuar con la herpetofauna de Honduras, James Randy McCranie ha publicado un segundo volumen sobre las serpientes, esta vez como único autor. El primero, en coautoría con L. D. Wilson, se publicó en 2002.

El libro tiene gran calidad editorial, buena impresión y un diseño tipográfico que facilita la consulta de los capítulos que lo componen; por ejemplo, en el canto lateral del libro, la primera página de cada capítulo lleva impresos los títulos de éstos, con la pestaña del capítulo correspondiente sombreada para su rápida localización; en la Literatura citada, el nombre de un autor que por primera vez aparece en la lista está con negritas, lo cual hace muy cómoda la búsqueda de referencias, y en la misma forma, en los índices al final del texto, cada letra del alfabeto destaca con toda claridad.

La reproducción de las 20 láminas en color es excelente. En términos generales las fotografías son buenas y con buen contraste, no obstante, me parece que algunas, en particuar aquellas de los hábitats, están oscuras y las de las especies, aunque de buena calidad, con 10 fotografías por página, la reducción hace que se pierdan detalles que es importante observar. La encuadernación del libro está bien cuidada y la cubierta a color resulta muy atractiva. Todas estas características siguen el mismo formato del volumen anterior.

En el prólogo, escrito por Jay Savage, quien leyó la mayor parte del cuerpo del libro en el manuscrito, previo a su publicación, se anticipa un segundo volumen que comprendería el resto de los reptiles. El autor presenta en el prefacio una breve narrativa sobre sus viajes a Honduras y un recuento de los principales productos publicados que se han derivado de esos estudios, los cuales incluyen el que aquí se reseña.

El libro está organizado en la siguiente forma: Materiales y métodos, Agradecimientos, El ambiente en Honduras,

Recibido: 19 septiembre 2011; aceptado: 30 septiembre 2011
Breve historia de la recolecta de reptiles en Honduras, Composición de la fauna de serpientes con claves bilingües (inglés y castellano) para las familias de serpientes de Honduras, Apuntes de especies -esta sección está en orden filogenético desde el nivel de familia-, Serpientes de probable distribución en Honduras, Distribución de las serpientes en Honduras, Estado de conservación de las serpientes de Honduras, Epílogo -recuerdos de los viajes de campo-, Láminas a color, Glosario, Nomenclátor de localidades de recolección, Literatura citada, Índice de nombres científicos e Índice de autores.

En la sección de Materiales y métodos, McCranie explica detalladamente la estructura de la parte medular del libro, es decir, los Apuntes por especie -que se inician a partir de familia-, uso de las claves de identificación, acrónimos de museo, ejemplares examinados y literatura consultada en busca del uso de nombre científico. Le siguen dos páginas de agradecimientos.

La parte principal del libro se inicia con el ambiente en Honduras; incluye varios mapas a color y en blanco y negro. Se dan descripciones detalladas, de la fisiografía, el clima, vegetación y generalidades del país.

En la breve historia de la recolección de reptiles en Honduras, McCranie reseña los trabajos que citan ejemplares recolectados en Honduras. Llama la atención que desde el punto de vista de McCranie estos trabajos hayan sido realizados únicamente por extranjeros y sólo unos cuantos por hondureños en colaboración con extranjeros. No hay mención de trabajos realizados sólo por hondureños. Quizá no existen, pero es evidente que en la obra que se reseña tampoco existe mención al libro de Gustavo Cruz Díaz (1987) de serpientes venenosas de Honduras.

Las siguientes dos secciones -Composición de la fauna de serpientes y Apuntes por especie- contienen la información de las 136 especies de serpientes. Están arregladas en 67 géneros y nueve familias. La primera parte, además de las claves para las familias de serpientes hondureñas, incluye un cuadro con las familias, sus géneros y el 
número de especies en cada uno de ellos. Las claves están bien ilustradas con dibujos o fotografías para identificar los caracteres que se mencionan y están en dos idiomas. Hubiera sido muy útil también traducir al castellano los pies de figura que apoyan estas claves. Revisándolas aleatoriamente, encontré algunos errores en la traducción, que no son atribuibles al autor.

En la sección de Apuntes por especie se hace una pequeña diagnosis de cada infraorden, familia, género y especie. Al nombre de la especie y autor sigue una lista de sinonimias, la distribución geográfica, descripción, diagnosis y especies parecidas -se distingue de otras especies de Honduras-, ilustraciones -referencias de ilustraciones de la especie-, observaciones, comentarios sobre su historia natural, etimología y ejemplares examinados. En esta misma sección hay claves para géneros y especies de los taxones con más de un género y una especie y mapas de distribución de las especies con los puntos de las localidades de recolección, en algunos mapas puede estar la distribución de más de una especie indicada.

No encontré mención de las subespecies reconocidas para cada taxón en los casos que así lo ameritan, lo cual me parece que sería muy importante. Si bien, el concepto de subespecie prácticamente ha caído en desuso (véase Comentarios en Flores-Villela, 1993 y Frost et al., 1992), la taxonomía de las serpientes está llena de nombres subespecíficos. Recientemente se han eliminado muchas subespecies para varios taxones; por ejemplo, entre 1992 y 2009 fueron elevadas a nivel de especie 145 subespecies para la fauna de reptiles de México. De esos nombres, 59 corresponden a serpientes. En relación con las sinonimias, el lector debe tener cuidado, pues como lo aclara McCranie en la sección Materiales y métodos, éstas se refieren a ejemplares provenientes de Honduras y no son listas completas de sinónimos.

De las serpientes que posiblemente se distribuyen en Honduras, McCranie nombra cuatro especies. La parte de distribución de las serpientes es bastante amplia. Analiza la distribución desde diferentes puntos de vista; primero por departamento, los 18 departamentos hondureños -estados, en el caso de otros países de Iberoamérica- en seguida, por tipos de vegetación, con la notación de si la distribución de la especie es amplia, periférica o restringida a determinado tipo de vegetación y, por último, la distribución altitudinal de cada especie.

Dos cuadros resumen la distribución por tipos de vegetación y por pisos altitudinales y dos secciones más completan la distribución por regiones fisiográficas (11) y regiones ecofisiográficas (39). McCranie analiza desde la biogeografía más tradicional e identifica 13 grandes patrones de distribución en la fauna hondureña de serpientes con base en sus límites distribucionales norte y sur. Siguiendo el esquema originalmente propuesto por Savage (1960), clasifica los géneros de serpientes de Honduras en cuatro unidades históricas. Para finalizar la sección de distribución, McCranie analiza las 50 especies cuya distribución termina en Honduras, sin contar las 20 especies endémicas del país, una introducida y las restantes cuya distribución va más allá de Honduras en ambas fronteras.

La parte de conservación se inicia con un relato poco común para un libro de este estilo, pero que desafortunadamente se ha vuelto muy común en América Latina y en otras partes del mundo. El crecimiento de la destrucción, el desplazamiento de poblaciones humanas nativas de ciertas áreas y el crimen contra los defensores de la naturaleza. McCranie describe un panorama muy completo del estado de conservación de la fauna hondureña de serpientes, y nadie mejor que él para hacerlo.

El análisis concluye que el $22.1 \%$ de las serpientes de Honduras son muy vulnerables; no obstante, de acuerdo con el autor, la mayoría de las especies endémicas presentan poblaciones estables. McCranie revisa el estatus de estas especies según la lista roja de la UICN y examina la presencia de las serpientes en las 30 áreas protegidas de Honduras, que muchas veces no funcionan como tales, según nos menciona el autor. Con excepción de 18, las especies de serpientes de Honduras han sido históricamente registradas para alguna de las áreas protegidas. Es de lamentar que para los amantes de la naturaleza y su conservación, el panorama de conservación no sea muy halagüeño en Honduras, como no lo es para muchos otros países de Centro América y del resto del continente. McCranie compara la salvaguardia de las áreas protegidas en Honduras con las de los Estados Unidos de América -dos sistemas que por desgracia no son equiparables-, y la comparación no favorece a Honduras, pues según opina McCranie, y con sobrada razón, el sistema de áreas protegidas de ese país comparte los mismos vicios y defectos de otros países de Latinoamérica.

El cuerpo del libro termina con relatos de las experiencias de campo del autor, quien tiene ya muchas horas de vuelo recolectando anfibios y reptiles en Honduras. En resumen, este libro es una excelente monografía de las serpientes de Honduras, todo aquel interesado en la fauna del Neotrópico, y en particular en este grupo, encontrará una fuente de información abundante. Felicito al autor y espero tener la oportunidad de ver el próximo volumen de los reptiles de Honduras.

\section{Literatura citada}

Cruz-Díaz, G. 1987. Serpientes venenosas de Honduras. Universidad Nacional Autónoma de Honduras, Tegucigalpa. $160 \mathrm{p}$. 
Flores-Villela, O. 1993. 60 años de herpetología en México. Reseña de "Synopsis of the Herpetofauna of México, vol. VII, Bibliographic addendum IV and index, bibliographic addenda II-IV 1979-1991, por H. M. Smith y R. B. Smith.1993.University Press of Colorado, 1082 p. Boletín de la Sociedad Herpetológica Mexicana 5:65-67.

Frost, D. R., A. G. Kluge y D. M. Hillis. 1992. Species in contemporary herpetology: comments on phylogenetic inference and taxonomy. Herpetological Review 23:46-54.

McCranie, R. J. y L. D. Wilson. 2002. The amphibians of Honduras. Society for the Study of Amphibians and Reptiles, Ithaca, New York. 625 p.

Savage, J. M. 1960. Evolution of a peninsular herpetofauna. Systematic Zoology 9:184-212. 